\title{
Quantitative assessment of distal radioulnar joint stability with pressure-monitor ultrasonography
}

\author{
Yuichi Yoshii ${ }^{*}$ (D), Hiroshi Yuine ${ }^{2}$, Wen-lin Tung $^{3}$ and Tomoo Ishii ${ }^{1}$
}

\begin{abstract}
Background: Diagnosing distal radioulnar joint (DRUJ) instability remains a challenge as it relies on physical examination. To quantitatively assess DRUJ stability, a pressure-monitor ultrasound system was developed. The objective of this study was to evaluate the force-displacement relationship of DRUJ in normal subjects.
\end{abstract}

Methods: Nine wrists of 9 asymptomatic volunteers were evaluated. The pressure-monitor ultrasound system was developed to apply pressure to the tissue with a pre-determined cycle and displacement of the transducer. Each subject was imaged sitting with the elbow flexed and forearm pronated. The dorsal surface of the distal radius and the center of the ulnar head were displayed at DRUJ level. The pressure toward palmar direction was applied to the distal ulna with different levels of transducer displacements, i.e., $1 \mathrm{~mm}, 2 \mathrm{~mm}$, and $3 \mathrm{~mm}$. The distance between the dorsal surface of the ulnar head and the dorsal surface of the distal radius was measured. The first measurement was performed at the initial position, and the second measurement was performed when the transducer pressed down the ulna to the degree that the ulnar head had shifted to the most palmar position. At the same time, the pressure to the transducer was measured. The changes of radioulnar distance (=the measurement at the most palmar position - the measurement at the initial position) and pressure, and pressure/distance ratio were compared among the different transducer displacements.

Results: The pressure was significantly increased as the transducer displacement became larger $(P<0.01)$. The changes of radioulnar distance were smaller in the $1 \mathrm{~mm}$ displacement condition compared to the 2 and $3 \mathrm{~mm}$ displacement conditions $(P<0.05)$. The pressure/distance ratio was larger in the $1 \mathrm{~mm}$ displacement condition compared to the 2 and $3 \mathrm{~mm}$ displacement conditions $(P<0.05)$.

Conclusions: A method to assess DRUJ stability by measuring changes in radioulnar distance and force application was developed. It was found that the application of $2 \mathrm{~mm}$ displacement and $200 \mathrm{~g}$ force was the critical stress for the capsuloligamentous structures to start stabilizing DRUJ. This methodology and the indices may be clinically useful to investigate the mechanical properties of patients with DRUJ instability.

Keywords: Distal radioulnar joint, Ultrasound, Pressure, Stability

\footnotetext{
* Correspondence: yy12721@yahoo.co.jp

${ }^{1}$ Department of Orthopaedic Surgery, Tokyo Medical University Ibaraki

Medical Center, 3-20-1 Chuo Ami, Inashiki, Ibaraki 300-0395, Japan

Full list of author information is available at the end of the article
}

(c) The Author(s). 2019 Open Access This article is distributed under the terms of the Creative Commons Attribution 4.0 International License (http://creativecommons.org/licenses/by/4.0/), which permits unrestricted use, distribution, and reproduction in any medium, provided you give appropriate credit to the original author(s) and the source, provide a link to the Creative Commons license, and indicate if changes were made. The Creative Commons Public Domain Dedication waiver (http://creativecommons.org/publicdomain/zero/1.0/) applies to the data made available in this article, unless otherwise stated. 


\section{Background}

Diagnosing distal radioulnar joint (DRUJ) instability remains a challenge because it relies on a physical examination. Since there is an increasing trend to treat DRUJ instability surgically, it is important to evaluate DRUJ instability accurately. It is known that DRUJ stability is found in the combination of bony anatomy, DRUJ capsule, musculotendinous structures, and ligamentous structures [1-10]. Because of these complex wriststabilizing structures, it is difficult to understand the pathological conditions for each structure.

Generally, DRUJ instability is assessed by several manual stress tests, such as the ballottement test, ulnocarpal stress test, and piano-key test. A previous biomechanical study using cadaver wrists demonstrated that the DRUJ ballottement test was the most reliable for evaluating the instability compared with other manual stress tests [11-13]. This clinical test evaluates the translation of the distal ulna relative to the distal radius in neutral forearm rotation by applying a dorsovolar shear force. An increased translation in comparison to the healthy side wrist may be caused by pathological conditions such as TFCC injury. Although this assessment can detect gross instability, this is a qualitative and subjective evaluation. Therefore, there are clinical needs to develop a method for the quantitative assessment of DRUJ instability.

There have been several studies for the evaluations of physiological translations for the DRUJ [14-22]. Some studies evaluated clinical DRUJ instability with computed tomography $(\mathrm{CT})[9,14]$. However, these methods cannot evaluate real situations with a dynamic forcedisplacement relationship. If it were possible to clarify the force-displacement relationship of DRUJ, it would be helpful to understand how much load the joint can withstand, in addition to discriminating pathological conditions quantitatively. It is important to develop a clinical method to evaluate the force-displacement relationship of DRUJ. To quantitatively assess DRUJ stability, a pressure-monitor ultrasound system was developed. In this study, we aimed to evaluate the force-displacement relationship of DRUJ in healthy volunteers and to characterize normal DRUJ stability.

\section{Methods}

The protocol for this study was reviewed and approved by our Institutional Review Board (No17-26). Nine wrists of nine asymptomatic volunteers (nine males; age range $23-35$, mean age 28.0 years) were evaluated by a pressure-monitor ultrasound system. Volunteers were excluded if they had a history of previous wrist trauma and wrist pain. Written consents were obtained from all study participants. All subjects were confirmed to have no instability in DRUJ with the ballottement test.

\section{Pressure-monitor ultrasound system}

The pressure-monitor ultrasound system was developed to apply pressure to the tissue with a pre-determined cycle and transducer displacement. The apparatus has two parts: a forearm table with a motor for the compression-release cycle, and a programmed controller (Fig. 1). The table was designed so that the transducer could be placed at the level of the subject's wrist and the placement adjuster could adjust the height of the transducer. The programmed controller could adjust the displacement and cycles in the range of $0.1-3.0 \mathrm{~mm}$ and 0.46-4.80 Hz (Gyouden Co., Tsukuba, Japan). For pressure measurement, a pressure sensor and a force processor (F381A, Unipulse, Co.) were attached to the system. This dynamic force processor was integrated with a strain gauge sensor that could measure waveforms of physical quantities, including pressure, load, and torque, and could take measurements at a frequency of 4000 times/s, which were saved as digital data on an SD card.

\section{Evaluations}

Each subject was tested sitting with the elbow flexed and the forearm pronated. The forearm of the examinee was secured to the table. The hand was positioned on an adjustable block such that the forearm was in a horizontal position. To stabilize the distal end of the radius, the blocks were placed below the distal radius and the pisiform bone. An ultrasound scanner (Hivision Avius; Hitachi Aloka Medical, Ltd., Tokyo, Japan) equipped with a linear array transducer was set to a depth of 20 $\mathrm{mm}$. At the distal radioulnar joint level, the transducer was maintained perpendicular to the longitudinal axis of the ulna (Fig. 1). The dorsal surface of the distal radius and the center of the ulnar head were displayed on a monitor. To determine the same measurement level in each volunteer, the highest aspect of the ulnar head was taken. The DRUJ motion during cyclic loading toward the palmar direction at the distal ulna was recorded. The compression-release cycles were applied with the pressure-monitor ultrasound system. The cycle was set to $1.5 \mathrm{~Hz}$. The pressure in the palmar direction was applied with different levels of transducer displacements, i.e., $1 \mathrm{~mm}, 2 \mathrm{~mm}$, and $3 \mathrm{~mm}$.

Using Analyze 10.0 Software (Biomedical Imaging Resource, Mayo Clinic, Rochester, MN), the recorded images were reviewed and the initial and final frames of the translation were chosen. The tangential line at the closest surface of the ulna to the transducer was defined. A parallel line to the ulna tangential line was drawn at the radius corner closest to the ulna. The distance from the transducer surface to the dorsal surface of the ulnar and radius was measured. In addition, the distance between the dorsal surface of the ulnar head and the dorsal 


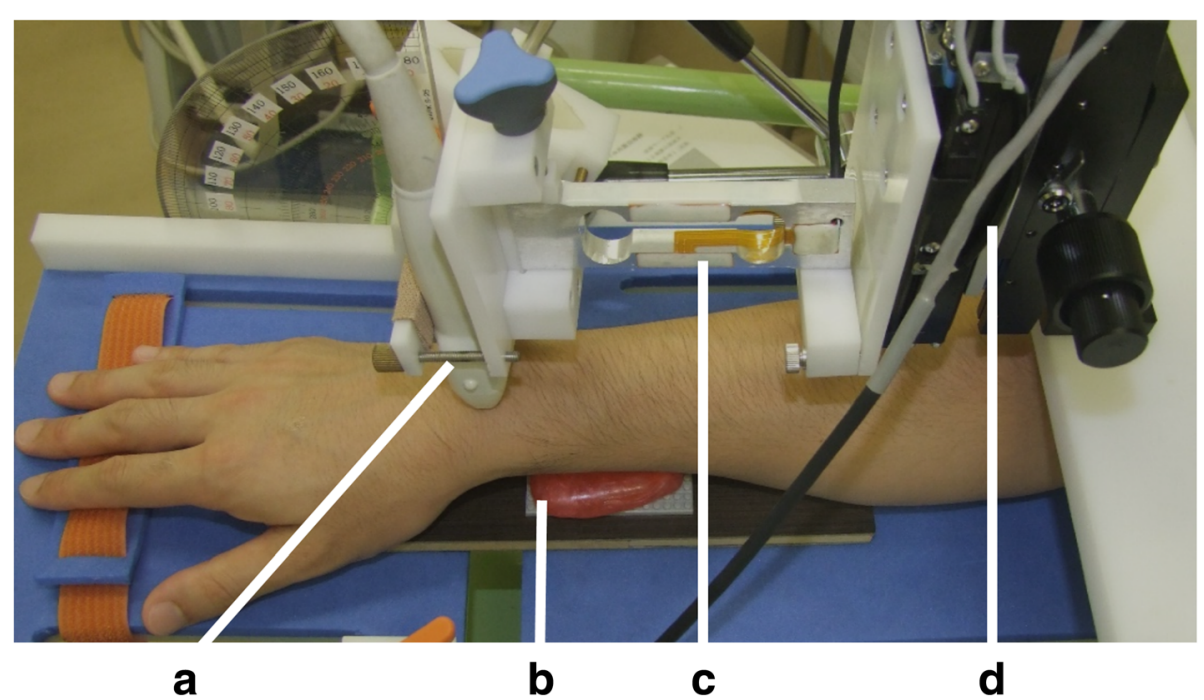

\section{Pressure monitor ultrasound system}

Fig. 1 Pressure-monitor ultrasound system and the setup for the measurements. The pictures show the forearm position. The pressure-monitor ultrasound system was developed to apply pressure to the tissue with a pre-determined cycle and transducer displacement. a Transducer, $\mathbf{b}$ block, $\mathbf{c}$ pressure sensor, and $\mathbf{d}$ motor

surface of the distal radius was measured (Fig. 2). The first measurement was performed at the initial position (A1), and the second measurement was performed when the transducer pressed down the ulna so that the ulnar head shifted to the most palmar position (A2). At the same time, the pressure to the transducer was measured. The pressure at the initial placement of the transducer was taken as the baseline, and the pressure when the transducer pressed down was measured (Fig. 3). The changes in ulna distance, radius distance, radioulnar distance $(=\mathrm{A} 1-\mathrm{A} 2, \mathrm{~mm})$, pressure (gram force, gf), and pressure/distance ratio were measured for five times in each transducer displacement condition. The averages of five measurements were used for analysis.

\section{Statistical analysis}

The results are expressed as mean \pm standard deviation. The changes of radioulnar distance, pressure, and pressure/displacement ratio were compared among the different transducer displacements. One-way repeated measures ANOVA was used. All results were expressed as mean \pm standard deviation. The parameters were considered statistically significant, when the $P$ value was less than 0.05. All analyses were performed using Excel Statistics 2012 (SSRI Co., Tokyo, Japan) and SPSS Statistics (IBM, Tokyo, Japan) software.

\section{Results}

The changes in radioulnar distances are shown in Fig. 4a. The changes of the ulna distances were $0.25 \pm 0.29$

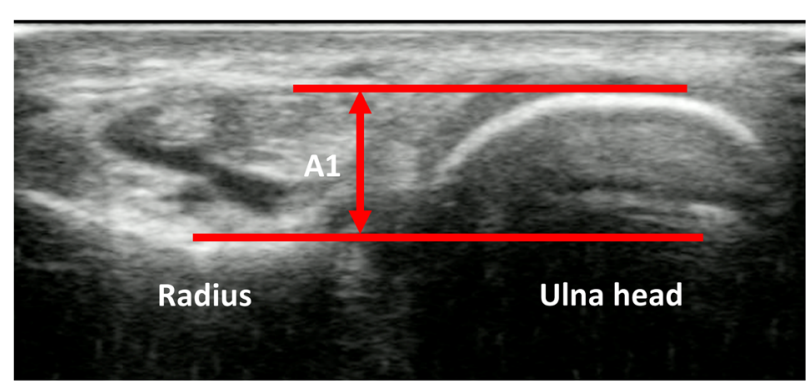

a

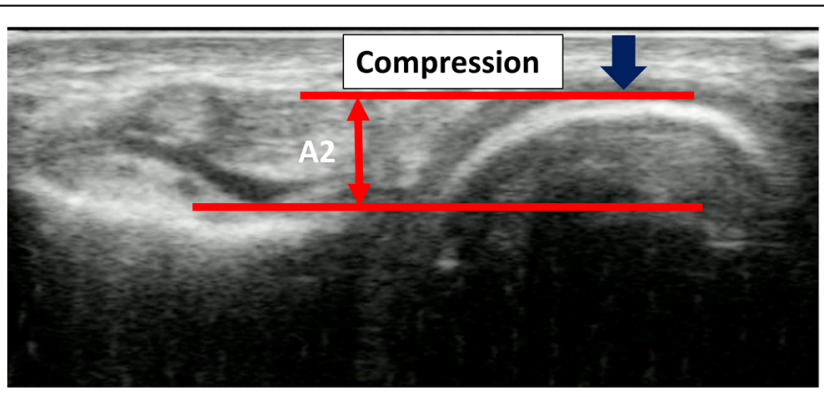

b

\section{An example of the ultrasound measurement}

Fig. 2 An example of an ultrasound measurement. a Initial position. A1: distance between the dorsal surfaces of the ulnar and the radius at the initial position. b Final position after compression. A2: distance between the dorsal surfaces of the ulnar and the radius at the final position after the compression. Arrow shows pressure to the ulna. A1-A2 were defined as the changes of radioulnar distance 


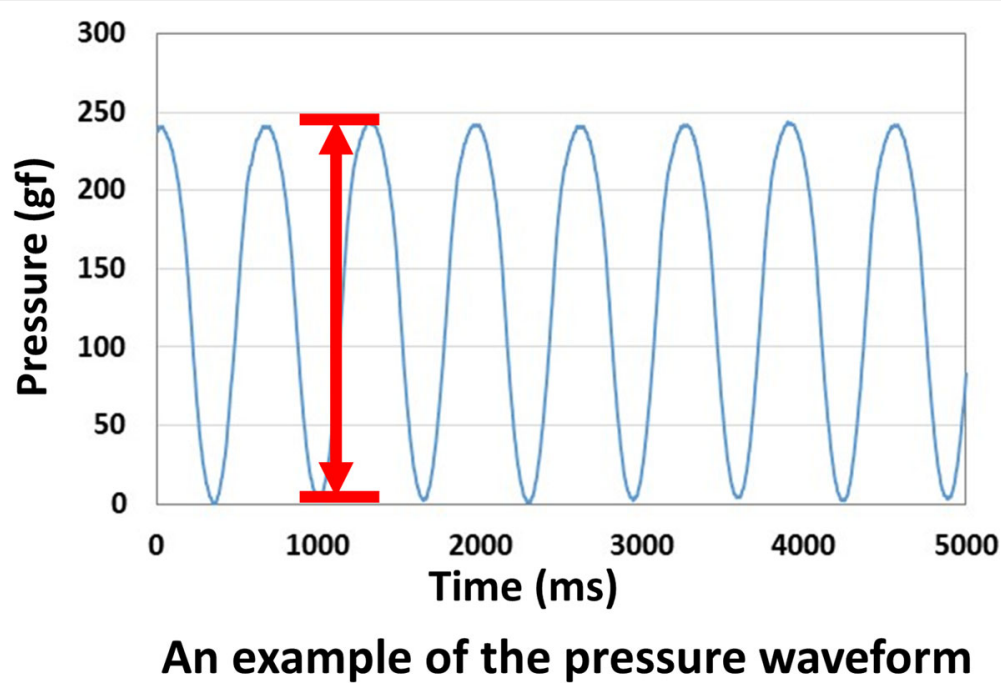

Fig. 3 An example of the pressure waveform. The pressure at the initial placement of the transducer was taken as the baseline and the pressure when the transducer pressed down was measured

$\mathrm{mm}, 0.27 \pm 0.20 \mathrm{~mm}$, and $0.38 \pm 0.30 \mathrm{~mm}$ for the $1 \mathrm{~mm}$, $2 \mathrm{~mm}$, and $3 \mathrm{~mm}$ displacement conditions, respectively. The changes of the radius distances were $0.35 \pm 0.29$ $\mathrm{mm}, 0.60 \pm 0.21 \mathrm{~mm}$, and $0.81 \pm 0.29 \mathrm{~mm}$ for the $1 \mathrm{~mm}$, $2 \mathrm{~mm}$, and $3 \mathrm{~mm}$ displacement conditions, respectively. The changes of the radioulnar distances were $0.10 \pm$ $0.06 \mathrm{~mm}, 0.34 \pm 0.16 \mathrm{~mm}$, and $0.44 \pm 0.22 \mathrm{~mm}$ for the 1 $\mathrm{mm}, 2 \mathrm{~mm}$, and $3 \mathrm{~mm}$ displacement conditions, respectively. There were no significant differences between the conditions for the changes of ulna distances. The changes of radius distances were significantly increased as the transducer displacement became larger $(P<0.01)$. There was a smaller change in radioulnar distance in the $1 \mathrm{~mm}$ displacement condition compared to the other conditions $(P<0.05)$. There was no significant difference in the radioulnar distance between the $2 \mathrm{~mm}$ and $3 \mathrm{~mm}$ displacement conditions.

The results of pressures are shown in Fig. 5. The pressures were $100.5 \pm 24.4$ gf, $205.2 \pm 31.1$ gf, and $296.8 \pm$ 43.9 gf for the $1 \mathrm{~mm}, 2 \mathrm{~mm}$, and $3 \mathrm{~mm}$ displacement conditions, respectively. The pressure/distance ratio results are shown in Fig. 5. The pressure/distance ratios were $1404.6 \pm 815.8 \mathrm{gf} / \mathrm{mm}, 809.6 \pm 597.0 \mathrm{gf} / \mathrm{mm}$, and $867.0 \pm 430.6 \mathrm{gf} / \mathrm{mm}$ for the $1 \mathrm{~mm}, 2 \mathrm{~mm}$, and $3 \mathrm{~mm}$ displacement conditions, respectively. The pressure was significantly increased as the transducer displacement became larger $(P<0.01)$. There was a significant difference between the $1 \mathrm{~mm}$ displacement condition and the other 2 and $3 \mathrm{~mm}$ displacement conditions for the pressure/distance ratio $(P<0.05)$.

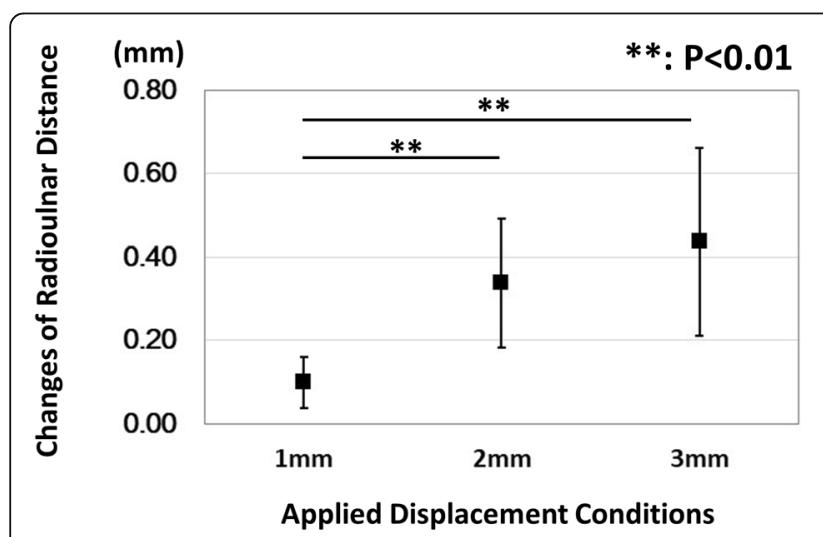

a Changes of Radioulnar Distance

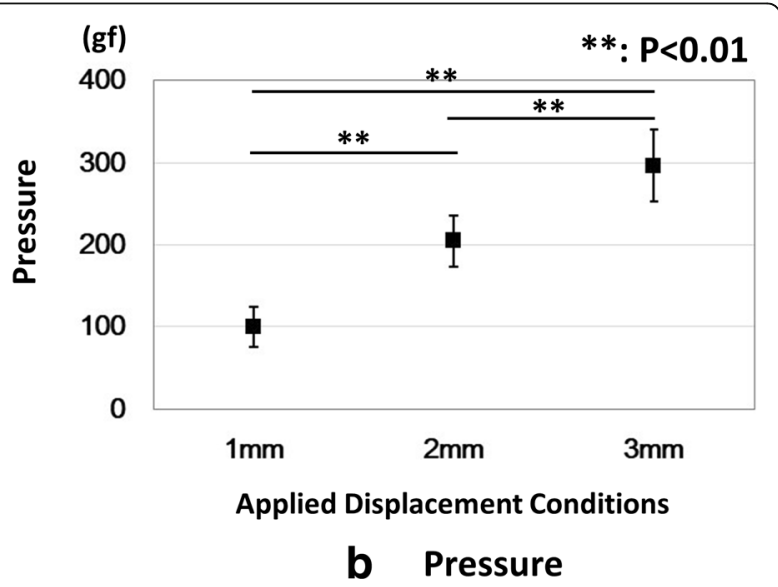

b Pressure

Fig. 4 Results for the changes of radioulnar distance and the pressure. Horizontal axis indicates the displacement conditions of the transducer. a Changes of the radioulnar distance. $\mathbf{b}$ Pressure. ${ }^{*}$ Showed significant differences between the conditions $(P<0.01)$ 


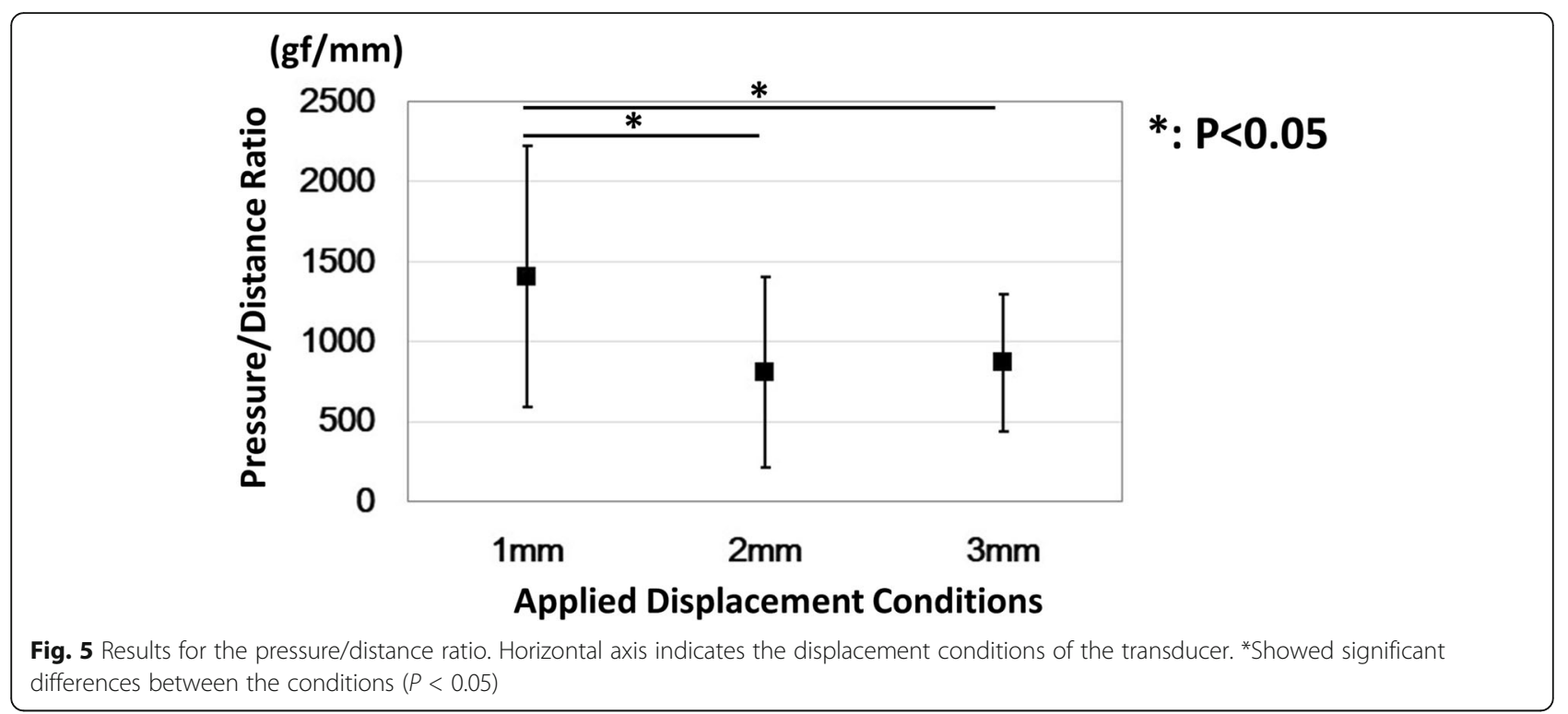

\section{Discussion}

DRUJ instability has been recognized as one of the common clinical problems around the wrist. Several methods have evaluated the amount of dorsovolar translation based on CT [14, 22-26]. There were radioulnar ratio method [22], radioulnar line method [23], epicenter method [24], and subluxation ratio method [25]. However, these methods are difficult to reproduce, need a CT scan, and sometimes there were poor inter-observer agreements. It is also difficult to understand dynamic force-displacement conditions. In this study, we assessed the utility of a pressure-monitor ultrasound system as a noninvasive method to assess the degree of physiological dorsovolar translation in healthy volunteers. Diagnostic ultrasound equipment is widely available. The basic advantages of ultrasound, such as rapidity, noninvasiveness, portability, and low costs, are well known. In addition, using a pressure-monitor system, we could evaluate the DRUJ force-displacement relation.

Before enrolling patients with DRUJ instability, we wanted to study in detail the normal force-displacement relationship, and it was characterized in this study. Originally, it was expected that the amount of radioulnar translation would be dependent on the amount of force applied. However, the results of radioulnar distance showed that there were significant differences between the $1 \mathrm{~mm}$ displacement condition and the other 2 or 3 $\mathrm{mm}$ displacement conditions. There were no significant differences between the $2 \mathrm{~mm}$ and $3 \mathrm{~mm}$ displacement conditions. The pressure-distance ratio also showed the same tendency. This suggested that there was a smaller change in the radioulnar distance in the DRUJ under the $1 \mathrm{~mm}$ displacement condition. When displacements more than $2 \mathrm{~mm}$ were applied, the changes in the radioulnar distance became more obvious. At the same time, the ligaments and soft tissues around DRUJ started to stabilize the joint. Under displacement control, the capsuloligamentous structures of the joint were stretched and limited displacement through a restraining force. Therefore, there were no significant changes in the radioulnar distance between the $2 \mathrm{~mm}$ and $3 \mathrm{~mm}$ displacement conditions even when the applied pressure was increased. Thus, the application of $2 \mathrm{~mm}$ displacement and $200 \mathrm{~g}$ force were the critical stress for the capsuloligamentous structures to start stabilizing DRUJ.

Compared with previous cadaveric studies, the amount of translation was lower because of the good dynamic stability through muscular contraction [17-19]. Although it is difficult to compare the results directly, the ratio of displacement to the force was about three quarters compared to the previous study [19]. This may be because the examination was performed with remaining the mobility of the radius. As this clinical test intended to be applied to the patient, it was not performed in the condition that the subject felt uncomfortable. The advantage of using this system to evaluate DRUJ instability is to measure pressure and displacement simultaneously. In the case of the patients with DRUJ instability, the displacement may be induced with weaker force. Thus, even less than $3 \mathrm{~mm}$ displacement condition, it will be possible to evaluate the DRUJ instability with the force-displacement relationship. Because we evaluated the stability with a gradual increase in the application of stress, we could identify these subtle changes in vivo. This method may be useful to discriminate pathological conditions from normal conditions.

There are several limitations in our study. First, we evaluated DRUJ instability only in the forearm pronation position. There was a report which showed that there 
was no radioulnar instability in the forearm full pronation position if the radioulnar ligament was intact [21]. Patterns of instability are dependent on forearm position [6]. Other forearm positions may need to be evaluated in future studies. Second, ultrasound measurements are known to be operator- and experience-dependent. Even though we aimed to develop reliable equipment, an experienced operator is still needed for accurate image acquisition. Third, the small sample size may be another limitation. We limited the number of subjects so that we could investigate normal variance in detail before trying to investigate a larger number of subjects or patients. Now that we have confirmed the method and values from normal subjects, we can compare these to patients with DRUJ instability. In addition, we can compare these results with other examiners for a reliability test. Finally, the relationship between the stability and pathology of the DRUJ is still unknown. It would be helpful to understand the pathophysiology better by evaluating the relationship between DRUJ instability and physical findings.

\section{Conclusions}

We used an ultrasound method to assess DRUJ stability by measuring changes in radioulnar distance and force application. This methodology and the indices of distance and pressure may be clinically useful to investigate the mechanical property of patients with DRUJ instability.

\section{Abbreviations \\ DRUJ: Distal radioulnar joint; TFCC: Triangular fibro cartilage complex; CT: Computed tomography; ANOVA: Analysis of variance}

\section{Authors' contributions}

YY contributed to the conception, design, analysis, and writing of the manuscript. HY contributed to acquire the data and analysis and revise the manuscript. WT contributed to the design and analysis and revise the manuscript. TO contributed to supervise the study and interpretation data and revise the manuscript. All authors read and approved the final manuscript.

\section{Funding}

This study was supported by the internal funds of the Tokyo Medical University Ibaraki Medical Center.

\section{Availability of data and materials \\ The datasets used and/or analyzed during the current study are available from the corresponding author on reasonable request.}

\section{Ethics approval and consent to participate}

The protocol for this study was reviewed and approved by our Institutional Review Board (No17-26). The committee members were Honda, Aoshiba, Furukawa, Ikegami, Suzuki, Higashitani, Aoyagi, Nagase, Maneyakma, Utsugi, Kurusu, Ookubo, Takahashi, Sugawara, and Yamamoto (titles omitted).

\section{Consent for publication}

Written consents for publication were obtained from all study participants.

\section{Competing interests}

The authors have no financial or personal relationships with other persons or organizations that may lead to a conflict of interest in this work.

\section{Author details}

'Department of Orthopaedic Surgery, Tokyo Medical University Ibaraki Medical Center, 3-20-1 Chuo Ami, Inashiki, Ibaraki 300-0395, Japan.
${ }^{2}$ Department of Rehabilitation, Tokyo Medical University Ibaraki Medical Center, Ami, Ibaraki 300-0395, Japan. ${ }^{3}$ Department of Occupational Therapy, Ibaraki Prefectural University of Health Sciences, Ami, Ibaraki 300-0394, Japan.

Received: 8 April 2019 Accepted: 11 June 2019

Published online: 27 June 2019

\section{References}

1. Kleinman WB, Graham TJ. The distal radioulnar joint capsule: clinical anatomy and role in posttraumatic limitation of forearm rotation. J Hand Surg Am. 1998;23:588-99 https://www.sciencedirect.com/science/article/pii/ S0363502398800439

2. af Ekenstam F, Hagert CG. Anatomical studies on the geometry and stability of the distal radio ulnar joint. Scand J Plast Reconstr Surg. 1985;19:17-25 https://www.ncbi.nlm.nih.gov/pubmed/4023639.

3. Kihara H, Short WH, Werner FW, Fortino MD, Palmer AK. The stabilizing mechanism of the distal radioulnar joint during pronation and supination. J Hand Surg Am. 1995;20:930-6 https://www.sciencedirect.com/science/ article/pii/S036350230580139X.

4. Nakamura T, Yabe Y, Horiuchi Y. Functional anatomy of the triangular fibrocartilage complex. J Hand Surg Br. 1996;21:581-6 https://www.ncbi.nlm. nih.gov/pubmed/9230938.

5. Schuind F, An KN, Berglund L, Rey R, Cooney WP 3rd, Linscheid RL, Chao EY The distal radioulnar ligaments: a biomechanical study. J Hand Surg Am. 1991;16:1106-14 https://www.sciencedirect.com/science/article/pii/ S0363502310800759.

6. Stuart PR, Berger RA, Linscheid RL, An KN. The dorsopalmar stability of the distal radioulnar joint. J Hand Surg Am. 2000;25:689-99 https://www. sciencedirect.com/science/article/pii/S0363502300195085.

7. Marès O. Distal rasioulnar instability. Hand Surg Rehabil. 2017;36:305-13. https://www.ncbi.nlm.nih.gov/pubmed/28865983.

8. Hotchkiss RN, An KN, Sowa DT, Basta S, Weiland AJ. An anatomic and mechanical study of the interosseous membrane of the forearm: pathomechanics of proximal migration of the radius. J Hand Surg Am. 1989; 14(2 Pt 1):256-61 https://www.sciencedirect.com/science/article/pii/ 0363502389900178 .

9. King GJ, McMurtry RY, Rubenstein JD, Ogston NG. Computerized tomography of the distal radioulnar joint: correlation with ligamentous pathology in a cadaveric model. J Hand Surg Am. 1986;11:711-7 https:// www.sciencedirect.com/science/article/pii/S0363502386800181.

10. Pfaeffle HJ, Fischer K, Manson TT, Tomaino MM, Woo SL, Herndon JH. Role of the forearm interosseous ligament: is it more than just longitudinal load transfer? J Hand Surg Am. 2000;25:683-8 https://www.sciencedirect.com/ science/article/pii/S0363502300512933.

11. Lindau T, Runnquist $K$, Aspenberg P. Patients with laxity of the distal radioulnar joint after distal radial fractures have impaired function, but no loss of strength. Acta Orthop Scand. 2002;73:151-6 https:/www.ncbi.nlm. nih.gov/pubmed/12079011.

12. Adams BD, Berger RA. An anatomic reconstruction of the distal radioulnar ligaments for posttraumatic distal radioulnar joint instability. J Hand Surg Am. 2002;27:243-51 https://www.sciencedirect.com/science/article/pii/ S0363502302983917.

13. Moriya T, Aoki M, Iba K, Ozasa Y, Wada T, Yamashita T. Effect of triangular ligament tears on distal radioulnar joint instability and evaluation of three clinical tests: a biomechanical study. J Hand Surg Eur. 2009;34:219-23 https://doi.org/10.1177/1753193408098482.

14. Pan CC, Lin YM, Lee TS, Chou CH. Displacement of the distal radioulnar joint of clinically symptom-free patients. Clin Orthop Relat Res. 2003:415:148-56 https://www.ncbi.n/m.nih.gov/pubmed/14612641.

15. GoftonWT GKD, Dunning CE, Johnson JA, King GJ. Comparison of distal radioulnar joint reconstructions using an active joint motion simulator. $J$ Hand Surg Am. 2005;30:733-42 https://www.sciencedirect.com/science/ article/pii/S0363502305000171.

16. Haugstvedt JR, Berger RA, Berglund LJ, Neale PG, Sabick MB. An analysis of the constraint properties of the distal radioulnar ligament attachments to the ulna. J Hand Surg Am. 2002;27:61-7 https://www.sciencedirect.com/ science/article/pii/S0363502302148040.

17. Pirela-Cruz MA, Goll SR, Klug M, Windler D. Stress computed tomography analysis of the distal radioulnar joint: a diagnostic tool for determining translational motion. J Hand Surg Am. 1991;16:75-82 https://www. sciencedirect.com/science/article/pii/S0363502310800176. 
18. Onishi T, Omokawa S, lida A, Nakanishi Y, Kira T, Moritomo H, Ruxasagluwang S, Kraisarin J, Shimizu T, Tanaka Y. Biomechanical study of distal radioulnar joint ballottement test. J Orthop Res. 2017;35:1123-7 https://doi.org/10.1002/jor.23355.

19. Deng J, Tian G, Wang L. Measurement of the shift in the distal radioulnar joint using a custom platform. Cell Biochem Biophys. 2015;73:413-6 https:// www.ncbi.nlm.nih.gov/pubmed/27352331.

20. Tay SC, Berger RA, Tomita K, Tan ET, Amrami KK, An KN. In vivo threedimensional displacement of the distal radioulnar joint during resisted forearm rotation. J Hand Surg Am. 2007;32:450-8 https://www.sciencedirect. com/science/article/pii/S0363502307001037.

21. Ward LD, Ambrose CG, Masson MV, Levaro F. The role of the distal radioulnar ligaments, interosseous membrane, and joint capsule in distal radioulnar joint stability. J Hand Surg Am. 2000;25:341-51 https://www. sciencedirect.com/science/article/pii/S0363502300396903.

22. Lo IK, MacDermid JC, Bennett JD, Bogoch E, King GJ. The radioulnar ratio: a new method of quantifying distal radioulnar joint subluxation. J Hand Surg Am. 2001;26:236-43 https:/www.sciencedirect.com/science/article/pii/ S0363502301141109.

23. Mino DE, Palmer AK, Levinsohn EM. The role of radiography and computerized tomography in the diagnosis of subluxation and dislocation of the distal radioulnar joint. J Hand Surg Am. 1983;8:23-31 https://www. sciencedirect.com/science/article/pii/S036350238380046X.

24. Wechsler RJ, Wehbe MA, Rifkin MD, Edeiken J, Branch HM. Computed tomography diagnosis of distal radioulnar subluxation. Skeletal Radiol. 1987; 16:1-5 https://link.springer.com/article/10.1007/BF00349919.

25. Park MJ, Kim JP. Reliability and normal values of various computed tomography methods for quantifying distal radioulnar joint translation. J Bone Joint Surg Am. 2008;90:145-53 https://www.ncbi.nlm.nih.gov/ pubmed/18171969.

26. Wijffels M, Stomp W, Krijnen P, Reijnierse M, Schipper I. Computed tomography for the detection of distal radioulnar joint instability: normal variation and reliability of four CT scoring systems in 46 patients. Skeletal Radiol. 2016;45:1487-93 https://www.ncbi.nlm.nih.gov/pubmed/27554667.

\section{Publisher's Note}

Springer Nature remains neutral with regard to jurisdictional claims in published maps and institutional affiliations.

Ready to submit your research? Choose BMC and benefit from:

- fast, convenient online submission

- thorough peer review by experienced researchers in your field

- rapid publication on acceptance

- support for research data, including large and complex data types

- gold Open Access which fosters wider collaboration and increased citations

- maximum visibility for your research: over $100 \mathrm{M}$ website views per year

At $\mathrm{BMC}$, research is always in progress.

Learn more biomedcentral.com/submissions 